\title{
PLUGGING SOCIAL RESPONSIBILITY INTO SHOPPER MARKETING
}

Dan Flint, University of Tennessee - Knoxville, USA

David W. Schumann, University of Tennessee - Knoxville, USA

The topic of in-store marketing has a long academic and practice history dating back to the early $20^{\text {th }}$ century (Schumann \& Davidson 2007; Schumann et al. 2008). Numerous papers have reflected aspects of the in-store environment and strategy. So it is interesting to note the resurgence of "shopper marketing" over the past ten years. Shopper marketing has been defined as "understanding how one's target consumers behave as shoppers and leveraging this intelligence to benefit the company or brand, consumers, retailers and shoppers" (Flint, 2009). Shopper marketing includes examining the way shoppers are influenced by various promotional activities such as couponing, packaging, in-store media, brand promotions and signage. Shopper marketing strategy addresses how retailers and brand manufacturers are trying to collaborate in new ways, supply chain execution of more engaging shopper marketing programs, and ways of engaging the consumer along the path to purchase and at that point of purchase while in a shopping "mode."

Many companies are moving to stress shopper marketing (Ad Age, 2009). The University of Tennessee has initiated the first academic/business forum on the topic. Initial partners include a number of the Fortune 500 major CPG companies, research groups, retailers, and the well-known practitioner based association, the In-Store Marketing Institute. One topic recently raised at a meeting of the members of this group was the importance of considering the strategic implications of shopper marketing on social responsibility.

This paper begins to address this concern by considering the means by which shopper marketing strategy can contribute to corporate social responsibility (CSR). As the figure and table reflect, CRS strategies must address both strategic planning and implementation. As one considers the benefit of shopper marketing programs, one must also consider the consequences of those programs as they reflect upon various aspects of social responsibility (e.g., environmental concerns, consumer health concerns, reinforcing economies in developing communities and nations). The ideas captured in the figure and table will be addressed in some detail and opportunities for discussion among participants will be encouraged.

References available upon request. 